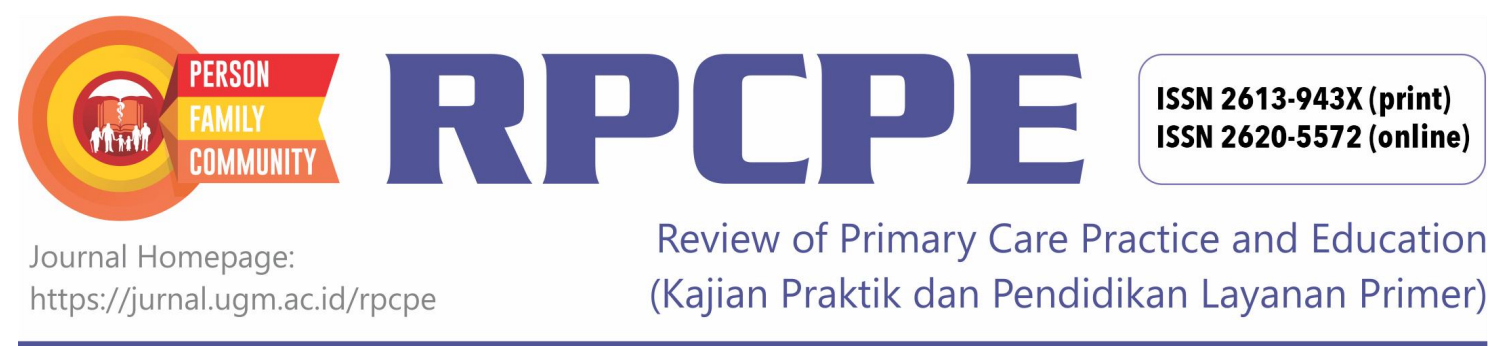

\title{
"Bonus of Demography" as an Opportunity to Build Indonesian's Welfare (Through the Role of Doctors in Primary Care in the STBM Program for Decreasing the Prevalence of Stunting)
}

\author{
Mariatul Fadilah \\ ${ }^{1}$ Department of Community Medicine and Public Health; Faculty of Medicine; Universitas Sriwijaya; Indonesia \\ Corresponding Author: \\ Mariatul Fadilah: Department of Community Medicine and Public Health; Faculty of Medicine; Universitas Sriwijaya, Jl. Mohammad \\ Ali, Komplek RSMH KM 3.5 Palembang, Sumatera Selatan - 30126, Indonesia \\ E-mail: mariatulfadilah@fk.unsri.ac.id \\ To cite this article: \\ Fadilah M. "Bonus of demography" as an opportunity to build indonesian's welfare (through the role of doctors in primary care in the \\ STBM program for decreasing the prevalence of stunting). Rev Prim Care Prac and Educ. 2019; 2(3): 92-94.
}

\section{INTRODUCTION}

Demographic bonus is a condition where the composition of the population of productive age (age range 15-65 years old) is greater than the number of non-productive age population. According to BPS predictions, in 20202045 Indonesia has the opportunity to experience a demographic bonus, in which the country will have around 180 million productive-aged people, while those who are not productive are 60 million. Currently, 3 to 4 unproductive people will be rewarded by 10 productive people. In 2018 the total population of Indonesia is 265 million with a composition of 133.17 million women and 131.88 million men, where the population dependency ratio of Indonesia is $47.9 \%$, which means there are 47 to 48 unproductive residents (aged under 15 years old and over 65 years old) who will be borne by 100 productive age population (15-65 years old). The problem is not the quantity of productive population but more towards its quality, so large a number will really make a bonus for the development of the Indonesian nation or on the contrary the explosion of population in this productive age will be a disaster for this beloved nation.

\section{DISCUSSION}

The Impact of Stunting on The Welfare of the Indonesian

Let's see what happens now. Productive population in the next 10 years to 20 years will be born now. Babies born today up to five years old will give color to the coming era of "Demographic Bonuses" in Indonesia. One of the priority health problems currently in Indonesia is Stunting. Stunting is a condition of length/height of children under the aged standard of children, and this is caused by a lack of long-term nutritional intake and recurrent infections where both of these causes influence each other. BPS noted, the prevalence of stunting of children under five in Indonesia in 2018 was $30.8 \%$ and the prevalence of stunting for children under five was $29.9 \%$. The indirect risk factors for the occurrence of stunting in Indonesia are still high, for example, the risk of chronic energy malnutrition in women of childbearing age in 2018 is $14.5 \%$, anemia in pregnant women is $48.9 \%$, and infants with low birth weight at age $0-59$ months at $6.2 \%$.

UNICEF, Perkins, et al., and Nshimyiryo, et al., reminds that the impact that can occur in the near future includes an increase in mortality and morbidity caused by a decrease in the body's immune system function so that children with stunting have a high mortality due to various types of diseases, family budget for health increase, academic and non-academic performance during poor school years ${ }^{1,2,3}$. The personality of stunted children who tend to be apathetic, isolated from the social environment, function deficits and brain development, can even decrease IQ 11 points due to stunting conditions. The situation of children stunted with poor motor development can also have an impact on the delay in the cognitive and psychosocial development of children which is achieved through exploring the environment by children where children are stunted with poor motor development, less likely to explore the environment due to their rudimentary motor development. Stunting in childhood will also waste their important period to grow so that stunted children tend to lose the opportunity to achieve the optimal potential they have. It can be estimated that the impact of stunting on the country, stunting can reduce the productivity of working age human resources so that it can hamper economic 
growth with a loss of $11 \%$ GDP (Gross Domestic Products) and can reduce HR income by $20 \%$. Improving morbidity numbers in the case of stunting will be impacted immediately on the Indonesian state budget in the health and economic sector.

\section{The Government Participation}

The Indonesian government realizes its important role in reducing the Stunting rate, through the Regulation of Ministry of Health Republic of Indonesia Number 3 of 2014 (Permenkes Nomor 3 Tahun 2014) concerning Community-Based Total Sanitation which aims to realize hygienic and sanitary community behavior independently in order to improve the highest degree of public health, where community participation is also involved in conducting monitoring and evaluation ${ }^{4}$. In the Regulation of Ministry of Health Republic of Indonesia Number 3 of 2014 also explained about the "5 Pillars of STBM", namely Stop Open Defecation, Hand Washing with Soap, Management of Household Drinking and Food Water, Safeguarding Household Waste, and Safeguarding Household Liquid Waste ${ }^{4}$. The five pillars above aim to break the chain of transmission of environmental-based diseases and poisoning due to improper food management and manifest each of the above points in married life. Through this policy, the Government tried to eliminate one of the indirect risk factors for Stunting.

Adekanmbi, Kayode, and Uthman stated that community participation in dealing with stunting is needed primarily in reducing stunting risk factors from the environment, namely the availability of clean water, sanitation and hygiene ${ }^{5}$. For example, washing hands properly, the availability of soap and the availability of water near latrines and access to clean water that is easily available. Spears, Ghosh, and Cumming, also stated that there was a decrease in the prevalence of stunting correlating with indiscriminate defecation behavior. This is more effective in reducing the prevalence of stunting compared to increasing access to healthy latrines in each household as well as an increase in households with healthy toilet access ${ }^{6}$. However, Briceno, Coville, and Martinez, stated that the number of latrines available was a benchmark for the success of sanitation programs, but more important changes in community behavior such as open defecation habits were still carried out even though access to healthy latrines was available ${ }^{7}$, while Spears, Ghosh, and Cumming, stated that if open defecation behavior increased by $10 \%$, then there was an increase in the prevalence of stunting by $0.7 \%$.

\section{The Importance of Improving Primary Health Care}

A large number of productive population and the existence of Government policies to overcome this problem cannot necessarily guarantee the success of the program. The difference in public awareness of the needs and importance of health for developing self-welfare is directly proportional to the awareness of the importance of improving health care in primary care, especially in the field of health promotion and disease prevention. Medical services that are oriented towards treatment (curative) will not solve health problems in Indonesia which will ultimately have an impact on people's quality of life.
Irwan, Craig and D'Souza, said behavior change in the community based on the Model of the Transtheoretical Model (stages of change) must be done deliberately carried out continuously like a cycle ${ }^{8,9}$. The ignorance and indifference of the community to a problem that has a negative impact, must be made an entry point in awakening the community itself. To acknowledge that their behavior is a problem is not easy, this condition is important because there is good communication from health workers to strengthen their intention to change their behavior. After the community is ready to initiate a commitment to change, it is necessary to provide assistance and further direction, then after the community changes its behavior must be motivated so that they continue to maintain and strengthen the new behavior that is better. Changing people's behavior requires the collaboration of competencies of medical personnel (doctors) and other health workers, from starting to determine the root of the problem in bad community behavior to mentoring and providing motivation so that healthy behaviors that have been formed are maintained. this also requires the contribution of policyholders from the center to the regions.

It is clear and very easy to understand that awareness of the community to change and maintain new behavior requires participation from all stakeholders in the health sector. The health community must also realize that health does not only belong to health actors. At present the community must be made aware that health is theirs, the dominance of the role of the community can apply healthy behavior and save Indonesian children from stunting to save the Indonesian nation from adversity through improving the quality of human resources in the future. It must be realized for this success, only collaboration between the professionalism of Doctors and Health Workers in Primary Care and public awareness, who can take advantage of "DEMOGRAPHIC BONUS" to be truly a "BONUS", not "DISASTER" for the Indonesian nation.

\section{REFERENCES}

1. United Nations Children's Fund (UNICEF), World Health Organization, International Bank for Reconstruction and Development/ The World Bank. Levels and trends in child malnutrition: Key findings of the 2019 Edition of the Joint Child Malnutrition Estimates. Geneva: World Health Organization. 2019 Licence: CC BY-NC-SA 3.0 IGO.

2. Perkins JM, Kim R, Krishna A, McGovern M, Aguayo VM, Subramanian SV. Understanding the association between stunting and child development in low-and middle-income countries: Next steps for research and intervention. Social Science \& Medicine. 2017 Nov 1;193:101-9.

3. Nshimyiryo A, Hedt-Gauthier B, Mutaganzwa C, Kirk CM, Beck $\mathrm{K}$, Ndayisaba A, et al. Risk factors for stunting among children under five years: a cross-sectional population-based study in Rwanda using the 2015 Demographic and Health Survey. BMC Public Health. 2019 Dec;19(1):175.

4. Director General of Disease Control and Environmental Health. The regulation of ministry of health Republic of Indonesia number 3 of 2014 about community-based total sanitation. Jakarta: Ministry of Health Republic of Indonesia. 2014.

5. Adekanmbi VT, Kayode GA, Uthman OA. Individual and contextual factors associated with childhood stunting in Nigeria: A multilevel analysis. Maternal \& Child Nutrition. 2013 Apr;9(2):244-59.

6. Spears D, Ghosh A, Cumming O. Open defecation and childhood stunting in India: An ecological analysis of new data from 112 districts. PloS One. 2013 Sep 16;8(9):e73784. 
7. Briceño B, Coville A, Martinez S. Promoting handwashing and sanitation: Evidence from a large-scale randomized trial in rural Tanzania. The World Bank. 2015 Jan 1.

8. Irwan. Health ethics and behavior. Ed I. Yogyakarta: CV. Absolut Media. 2017.

9. Craig SL, D’Souza S. Transtheoretical model of change. Oxford University Press. 2018 June 27. doi: 10.1093/OBO/97801953896780268 . 